WEISMAN, R. G. Some determinants of inhibitory stimulus control. Journal of the Experimental Analysis of Behavior, 1969, 12 , $443-450$.
NOTE

1. This research was supported in part by a grant from the Research Council of the University of North Carolina at Greensboro.

\title{
Lysergic acid diethylamide and a novel stimulus
}

\author{
EDWARD T. UYENO, Stanford Research \\ Institute, Menlo Park, Calif. 94025
}

The mean running time of rats injected with $0.016 \mathrm{mg} / \mathrm{kg}$ of lysergic acid diethylamide (LSD-25) was not significantly different from that of others, administered saline solution. However, when a novel stimulus (hurdle) was presented in the runway, the mean running time of the experimental group was significantly longer than that of the control group.

In an underwater swim test, Uyeno (1968) found that animals injected with lysergic acid diethylamide (LSD-25) took a significantly longer time to begin responding to a confronting stimulus, despite the fact that their performance involving the motor coordination was not significantly affected. To test further the effects of LSD-25 on the behavior of animals given a confronting stimulus, two runway experiments, one without and the other with an "unexpected" obstacle, were conducted.

\section{EXPERIMENT 1}

Twenty male rats of the Wistar strain weighing 190 to $210 \mathrm{~g}$, deprived of food for $22 \mathrm{~h}$, were trained to run a grey straight runway $(118 \times 12 \times 5 \mathrm{~cm})$ for a piece of food pellet. A trial was initiated by placing an animal in the startbox and by lifting the guillotine door to allow the animal to enter the alley and to run into the foodbox. Running time was recorded by starting a timer when the animal entered the alley and by stopping it when the animal entered the foodbox. After 16 distributed trials, when their running times had stabilized, they were ranked according to the mean running times of their last three trials. On the basis of their ranks, they were assigned equally to experimental and control groups to form 10 matched pairs. The experimental animals were injected intraperitoneally (i.p.) with $0.016 \mathrm{mg} / 2.5 \mathrm{ml} / \mathrm{kg}$ of LSD-25 in saline solution, whereas the control animals were administered $0.9 \%$ saline solution. Fifteen minutes after the injection, each animal, under $22 \mathrm{~h}$ of food deprivation, was given one trial in the runway, and its running time was recorded.

\section{EXPERIMENT 2}

Forty male rats, essentially similar to the ones used in the first experiment, were also trained to run the runway. They were ranked according to their running times and assigned equally to experimental and control groups in a similar manner as described previously. The experimental animals were injected (i.p.) with a dose of LSD-25, equivalent to the dose administered to the experimental animals in the first experiment, while the control animals were injected with saline. Fifteen minutes after the injection, the runway test was conducted in a similar manner as described in the first experiment, except for the introduction of a novel stimulus. A white metal hurdle, $3 \mathrm{in}$. in height, was erected in the nunway $10 \mathrm{in}$. in front of the foodbox.

\section{RESULTS AND DISCUSSION}

The data of the first experiment show that after the injection, the mean running time of the experimental group is not significantly different from that of the control group (Table 1). This finding suggests that the LSD-25-treated animals

Table 1

Analysis of Mean Running Time

\begin{tabular}{|c|c|c|c|c|c|c|}
\hline \multirow{2}{*}{$\begin{array}{l}\text { Experi- } \\
\text { ment }\end{array}$} & \multicolumn{2}{|c|}{ Before Injection } & \multicolumn{4}{|c|}{ After Injection } \\
\hline & Experimental & Control & Experimental & Control & $t$ & Significance \\
\hline \multirow{3}{*}{1} & \multicolumn{2}{|c|}{ (Sec) } & \multicolumn{2}{|c|}{$\begin{array}{c}\text { No Hurdle } \\
\text { (Sec) }\end{array}$} & & \\
\hline & 2.9 & 3.0 & 2.9 & 2.4 & 1.47 & N.S. \\
\hline & \multicolumn{6}{|c|}{ Hurdle } \\
\hline 2 & 3.3 & 3.3 & 120.8 & 85.9 & 2.21 & $5 \%$ \\
\hline
\end{tabular}

showed no apparent disruption of motor coordination. However, the results of the second experiment show that the mean running time of the experimental animals is significantly longer than that of the control animals $(t=2.21, \quad d f=1) \quad$ (Table 1$)$. Moreover, 10 experimental animals did not go over the hurdle within the time limit of $3 \mathrm{~min}$, whereas only four control animals failed. This difference is significant at the $5 \%$ level $\left(\chi^{2}=3.96, \mathrm{df}=1\right)$.

The finding that more experimental animals than control animals hesitated when the novel "unexpected" stimulus was presented is in accord with that of Uyeno (1968), who found that LSD-25-treated animals, placed in a startbox and submerged in water, showed a greater increase in starting latency than did control animals, despite no significant difference in swimming time. The present results are also consistent with those of Appel et al (1967), who trained rats to turn a wheel to escape shock and found that LSD-25 significantly increased their escape latency (i.e., the time they took to begin responding when the foot shock was presented) but did not significantly increase their rate of wheel turning. The hesitation in climbing the hurdle, the delay in emerging from the startbox, and the slowness in initiating the escape response seem to indicate that the hallucinogen disrupts the perception (Schwartz \& Cheney, 1965) of a novel obstacle and of a starting stimulus, such as the opening of the underwater startbox door and the administration of foot shock. Moreover, the compound appears to interrupt the transmission of sensory impulses at the level of the lateral geniculate (Evarts \& Marshall, 1965) and in the hippocampal system of the temporal lobe (Adey et al, 1962).

\section{REFERENCES}

ADEY, W. R., BELL, F. R., \& DENNIS, B. J. Effects of LSD-25, psilocybin, and psilocin on temporal lobe EEG pattems and learned behavior in the cat. Neurology, 1962, 12, 591-602.

APPEL, J. B., FREEDMAN, D. X., \& FILBY, Y. $M$. The effects of three psychoactive drugs on two varieties of escape behavior. Archives Internationales de Pharmacodynamie et de Thérapie, 1967, 167, 179-193.

EVARTS, E. V., \& MARSHALL, W. H. The effects of lysergic acid diethylamide on the excitability cycle of the lateral geniculate. Transactions of the American Neurological Association, 1965, 80, 58-60.

SCHWARTZ, A. S., \& CHENEY, C. Retinal effects of high doses of LSD in the cat. Experimental Neurology, 1965, 13, 273-282.

UYENO, E. T. Hallucinogenic compounds and swimming response. Journal of Pharmacology \& Experimental Therapeutics, 1968, 159, 216-221.

NOTE

1. This work was supported by Grant MH-16124 from the National Institutes of Health, U. S. Public Health Service. 